\title{
Encontrabilidade da informação em repositórios institucionais: uma proposta de instrumento de avaliação
}

\author{
Natália Carvalho Custódio \\ Graduando em Biblioteconomia da Universidade Federal do Rio Grande do Norte (UFRN). Bolsista de \\ Iniciação Científica da Pró-Reitoria de Pesquisa/UFRN (PROPESQ-IC) \\ E-mail: nataliaccustodio@gmail.com \\ Fernando Luiz Vechiato \\ Professor do Departamento de Ciência da Informação da Universidade Federal do Rio Grande do \\ Norte (UFRN) \\ E-mail: vechiato2008@gmail.com
}

\begin{abstract}
RESUMO:
A encontrabilidade da informação é um elemento que se situa entre as funcionalidades de um ambiente informacional analógico, digital ou híbrido e as características dos sujeitos informacionais. Levando em consideração o avanço das Tecnologias de Informação e Comunicação que impulsionou a visibilidade da comunidade científica, dando destaque aos Repositórios Institucionais, que reúnem toda a produção técnicocientífica da comunidade universitária (docentes, técnicos administrativos e alunos de pós-graduação) da instituição competente, com o objetivo de armazenar, preservar e disponibilizar textos completos de acesso livre. O presente trabalho tem como objetivo demonstrar os atributos da encontrabilidade da informação no Repositório Institucional da Universidade Federal do Rio Grande do Norte. A partir de uma pesquisa bibliográfica e descritiva, com abordagem qualitativa, onde foi utilizada a técnica de observação individual, foi realizada uma breve análise desses atributos no ambiente informacional em questão, tornando possível a elaboração de um checklist que ao ser aplicado no ambiente escolhido para a análise percebemos que ele atende a maioria das necessidades informacionais de seus usuários, mas ainda assim precisa de melhorias para propiciar uma encontrabilidade da informação completa para os seus usuários.
\end{abstract}

Palavras-chave: Encontrabilidade da informação. Repositórios institucionais. Atributos da encontrabilidade da informação. Repositório institucional da UFRN.

\section{ABSTRACT:}

The findability of information is an element which is situated between the informational environment features analog, digital, or hybrid and the characteristics of the informational subjects. Taking into account the advancement of information and communication technologies that boosted the visibility of the scientific community, giving prominence to Institutional Repositories, bringing together all the technical and scientific production of the University community (Faculty, administrative technicians and graduate students) of the competent institution, in order to store, preserve and make available full texts of free access. The present work aims to demonstrate the attributes of the findability of information in the institutional repository of the Universidade Federal do Rio Grande do Norte. From a literature search and descriptive, with a qualitative approach, where we used the technique of individual observation, a brief analysis of these attributes in the informational environment in question, making it possible to draw up a checklist to be applied in the environment 
chosen for the analysis we noticed he meets most of the informational needs of its users, but still needs improvements to support findability of complete information for your users.

Keywords: Findability of information. Institutional repositories. Attributes of the findability of information. Institutional repository of UFRN.

\section{INTRODUÇÃO}

A sociedade contemporânea experimenta novas possibilidades de produção, organização, preservação, disseminação e acesso à informação, proporcionadas pelo desenvolvimento tecnológico.

Diante desse contexto, entendemos que com o avanço das Tecnologias de Informação e Comunicação (TIC), a visibilidade da comunidade científica foi impulsionada, dando destaque aos Repositórios Institucionais (RI), que reúnem toda a produção técnico-científica da comunidade universitária (docentes, técnicos administrativos e alunos de pós-graduação) da instituição competente, com o objetivo de armazenar, preservar e disponibilizar textos completos de acesso livre.

De acordo com Vechiato e Vidotti (2014), a encontrabilidade da informação "sustenta-se fundamentalmente na interseção entre as funcionalidades do ambiente informacional e as características dos sujeitos informacionais". Esses autores definiram treze atributos que promovem a encontrabilidade da informação em ambientes informacionais, quais sejam: taxonomias navegacionais; instrumentos de controle terminológico; folksonomias; metadados; mediação dos informáticos; affordances; wayfinding; descoberta de informações; acessibilidade usabilidade; mediação dos profissionais da informação; mediação dos sujeitos informacionais; intencionalidade; e mobilidade, convergência e ubiquidade.

Levando em consideração apenas os atributos que podem ser aplicados em repositórios institucionais, elaboramos um checklist que possibilita visualizar esses atributos que promovem a encontrabilidade da informação no ambiente informacional digital em questão.

\section{REPOSITÓRIOS INSTITUCIONAIS}


Os Repositórios Institucionais (RI) reúnem toda a produção técnico-científica da comunidade universitária (docentes, técnicos administrativos e alunos de pósgraduação) da instituição competente, e possuem como objetivo armazenar, preservar e disponibilizar textos completos de acesso livre.

Os avanços tecnológicos da comunicação e da informação (TIC) permitiram
o surgimento de redes de comunicação eletrônica, revolucionando os fluxos
de informação, forma de acesso e troca de informações ampliando o espiral
do conhecimento, graças a um novo parâmetro espaço-tempo possibilitado
pelas tecnologias. A transmissão de dados ocorre instantaneamente graças
à convergência tecnológica com as telecomunicações e com a micro-
eletrônica. Esses são os instrumentos e as relações que servem de base para
a Sociedade da Informação (SI). O século XXI consolida esse formato da
informação- -eletrônica. A internet possibilitou acesso às fontes de informaçãa
sendo relevante o correio eletrônico, a Web, listas de discussão - permitem a
troca de informações entre os especialistas, blogs, chats - a disponibilização
de versões preliminares de artigos de periódicos e de comunicações em
conferências científicas, de capítulos de livros, publicações periódicas
eletrônicas materiais de ensino bases de dados, compilações de dados
eletrônicos, e os repositórios, dentre outros. Essas mudanças influenciarão,
sobremaneira, a disseminação da produção científica e as relações de
comunicação da informação no ambiente acadêmico (SAYÃO et al., 2009, p.
7).

Gomes e Rosa (2010, p. 153) afirmam que a maioria das instituições que adotam a utilização dos RI são universidades, pois thes garantem visibilidade institucional a partir da disponibilização da produção científica dos seus colaboradores, alunos e professores, e ao mesmo tempo prestam um serviço público a toda a comunidade a partir da disponibilização gratuita da documentação científica. Por isso podemos entender que:

\begin{abstract}
Repositórios institucionais são entendidos hoje como elementos de uma rede ou infraestrutura informacional de um país ou de um domínio institucional destinados a garantir a guarda, preservação a longo prazo e, fundamentalmente, o livre acesso à produção científica de uma dada instituição (SAYÃO et al., 2009, p. 12).
\end{abstract}

Sayão et al. (2009, p. 10) complementa essa informação afirmando que esses repositórios são, portanto, serviços organicamente vinculados às instituições de forma cumulativa e persistente, comprometidos com a memória, preservação de longo prazo e com o acesso livre a informação científica.

Rodrigues (2011) chama a atenção para o fato dos Rls guiarem o fluxo comunicacional da produção científica, o qual permite à rápida e eficaz disseminação da produção científica visando à disponibilização de objetos digitais submetidos pela 
comunidade acadêmica através da política do auto arquivamento, sendo constituídos, em sua maioria, por dissertações, teses e artigos.

Cada RI possui sua política determinada de acordo com os objetivos da instituição a qual ele esteará vinculado, no entanto, todos partem do mesmo pressuposto de armazenar, preservar e disseminar a informação.

Esses Rls trazem a iniciativa do auto depósito, em que o docente, técnico administrativo e/ou aluno de pós-graduação depositará a sua própria produção científica para que ela esteja disponível em acesso livre para qualquer usuário do RI. Essa iniciativa é importante, pois incentiva o membro da instituição a divulgar a sua produção acadêmica, possibilitando, a partir da política de acesso livre, aos outros usuários o uso dessa informação para fins não lucrativos. No entanto, essa iniciativa não é regra, pois o sistema permite que essa inserção seja feita por outra pessoa, alguém responsável pelo repositório, por exemplo, isso vai depender da política adotada pela instituição referente ao repositório.

\begin{abstract}
A afirmação dos repositórios institucionais, e a generalização do hábito do auto-arquivo, passará pela criação de serviços de valor acrescentado para os investigadores (geração de relatórios de avaliação, citações, estatísticas, que os recompensem dos minutos adicionais que devem gastar a auto-arquivar) e serviços de apoio ao auto-arquivo (como o esclarecimento de direitos de autor). Mas o que parece fundamental é a adopção formal, por parte das instituições (universidades, departamentos, centros de investigação, organismos financiadores), de políticas que premeiem ou tornem mesmo obrigatório o depósito da produção científica nos repositórios institucionais ou outros sistemas de acesso livre (RODRIGUES, 2004, p. 32).
\end{abstract}

\title{
3 ENCONTRABILIDADE DA INFORMAÇÃO
}

O conceito de encontrabilidade da informação utilizado nesta pesquisa resulta do cenário paradigmático que privilegia o acesso à informação com ênfase nas necessidades, competências, comportamentos e características dos usuários para a organização da informação. (VECHIATO; VIDOTTI, 2014).

De acordo com Vechiato e Vidotti (2014), o termo encontrabilidade, traduzido do inglês 'findability', foi definido preliminarmente por Peter Morville (2005) em uma perspectiva mais técnica que científica.

Vechiato e Vidotti (2014, p. 164) afirmam que "a encontrabilidade da informação sustenta-se fundamentalmente na interseção entre as funcionalidades de um ambiente informacional e as características dos sujeitos informacionais". 
Os autores ainda afirmam que:

\begin{abstract}
São suas experiências, competências e comportamentos em relação a informação que subsidiam a elaboração de técnicas e tecnologias a serem aplicadas nas arquiteturas da informação, o que possibilita ao sujeito encontrar aquele de que necessita e/ou descobrir acidentalmente uma informação que, conquanto não seja a sua prioridade em uma situação de busca, está atrelada a uma necessidade em segundo plano ou inconsciente (VECHIATO; VIDOTTI, 2014, p. 164).
\end{abstract}

Com base nessas afirmações, os autores apresentaram os principais atributos da encontrabilidade da informação (AEI) e sua manifestação em ambientes informacionais e arquiteturas da informação.

Esses atributos são: taxonomias navegacionais, instrumentos de controle terminológico, folksonomias, metadados, mediação dos informáticos, affordances, wayfinding, descoberta de informações, acessibilidade e usabilidade, mediação dos profissionais da informação, mediação dos sujeitos informacionais, intencionalidade e mobilidade, convergência e ubiquidade.

Dentre esses atributos, abordamos apenas os aplicáveis em repositórios institucionais, tendo como base o RI UFRN.

\title{
4 METODOLOGIA
}

Essa pesquisa se caracteriza como uma pesquisa bibliográfica e descritiva, com abordagem qualitativa, onde foi utilizada a técnica de observação para possibilitar a elaboração do checklist com base nos atributos da Encontrabilidade da Informação propostos por Vechiato e Vidotti (2014).

Para Marconi e Lakatos (2010), a pesquisa bibliográfica compreende oito fases distintas: escolha do tema; elaboração do plano de trabalho; identificação; localização; compilação; fichamento; análise e interpretação e redação.

A pesquisa bibliográfica foi necessária para possibilitar a compreensão do tema, repositórios institucionais, encontrabilidade da informação e mediação infocomunicacional.

No que diz respeito à abordagem qualitativa, Neves (1996, p. 1) afirma que:

[...], a pesquisa qualitativa costuma ser direcionada, ao longo do seu desenvolvimento; além disso, não busca enumerar ou medir eventos e, geralmente, não emprega instrumental estatístico para análise dos dados; 
seu foco de interesse é amplo e parte de uma perspectiva diferenciada de adotada pelos métodos quantitativos. Dela faz parte à obtenção de dados descritivos mediante contato direto e interativo do pesquisador com a situação objeto de estudo. Nas pesquisas qualitativas, é frequente que o pesquisador procure entender os fenômenos, segunda a perspectiva dos participantes da situação estudada e, a partir, daí situe sua interpretação dos fenômenos estudados.

Para Marconi e Lakatos (2010), a observação é uma técnica de coleta de dados e utiliza os sentidos na obtenção de determinados aspectos da realidade. Não consiste apenas em ver e ouvir, mas também em examinar fatos ou fenômenos que se deseja estudar. Essa técnica ajuda o pesquisador a identificar e a obter provas a respeito de objetivos sobre os quais os indivíduos não possuem consciência, mas que orientam seu comportamento.

Para Selltiz (1965, p. 233, apud MARCONI; LAKATOS, 2010, p. 174), a observação torna-se científica à medida que: convém a um formulado plano de pesquisa; é planejada sistematicamente; é registrada metodicamente e está relacionada a proposições mais gerais e está sujeita a verificações de controles sobre a validade e segurança.

O método de observação foi escolhido por possibilitar a coleta de dados sobre um conjunto de atitudes comportamentais típicas. A observação foi feita com o objetivo de identificar as ações efetuadas pelos diferentes moderadores no ambiente escolhido, levando em consideração que a pesquisadora realiza estágio no ambiente estudado, possibilitando uma ponderação de cada ação de forma real registrando-se os dados à medida que ocorrem.

A observação foi individual, ou seja, realizada por um pesquisador, trazendo um ponto positivo e um ponto negativo de acordo com Marconi e Lakatos (2010). Em relação ao ponto positivo, a observação individual pode intensificar a objetividade de suas informações, indicando, ao anotar os dados, quais são os eventos reais e quais são as interpretações. Em relação ao ponto negativo, a personalidade do pesquisador pode influenciar e tornar a análise tendenciosa, o que pode ser considerada uma limitação desta pesquisa.

\section{OBSERVAÇÃO DOS ATRIBUTOS DA ENCONTRABILIDADE DA INFORMAÇÃO NO REPOSITÓRIO INSTITUCIONAL DA UFRN}


Vechiato e Vidotti (2014) definem treze atributos da encontrabilidade da informação aplicáveis em ambientes informacionais, constatamos que apenas alguns deles são aplicáveis em repositórios institucionais, são eles: taxonomias navegacionais, folksonomias, instrumentos de controle terminológico, metadados, mediação dos informáticos, mediação dos profissionais da informação, mediação do sujeito informacional e intencionalidade, affordances, waydfinding e a descoberta de informações.

As taxonomias navegacionais são instrumentos para organização da informação que propiciam a encontrabilidade da informação em ambientes informacionais.

De acordo com Vechiato e Vidotti (2014) as taxonomias podem ser utilizadas para a estruturação do conteúdo informacional, de forma que visam apoiar a encontrabilidade da informação através dos mecanismos de busca e/ou apresentando a informação por meio de categorias informacionais em que o conteúdo será recuperado via navegação.

Figura 1 - Exemplos de taxonomia no RI UFRN

Comunidades e coleçōes

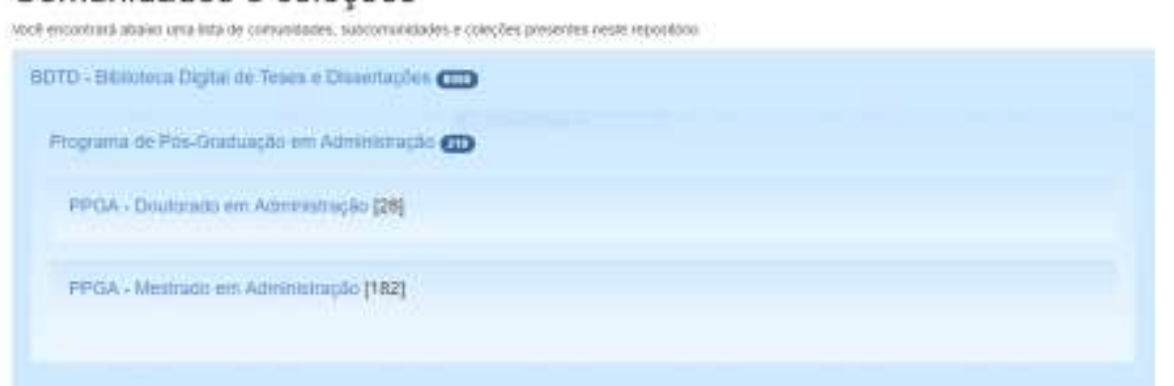

Fonte: http://repositorio.ufrn.br/>. Acesso em: 10 jun. 2016.

As folksonomias, de acordo com Vechiato e Vidotti (2014), estão relacionadas à organização social da informação que propicia ao sujeito a classificação de recursos informacionais, bem como encontrar a informação por meio da navegação (uma nuvem de tags, por exemplo) ou dos mecanismos de busca, ampliando as possibilidades de acesso.

A descrição por metadados é um elemento essencial para o funcionamento do RI. Para Vechiato e Vidotti (2014) metadados são, de forma sintética, dados que descrevem, neste caso, as páginas web, os recursos informacionais contemplados e 
as ligações entre eles, visando atribuir significado. Eles são indispensáveis, pois são utilizados pelos mecanismos de busca para encontrar a informação.

Figura 2 - Metadados

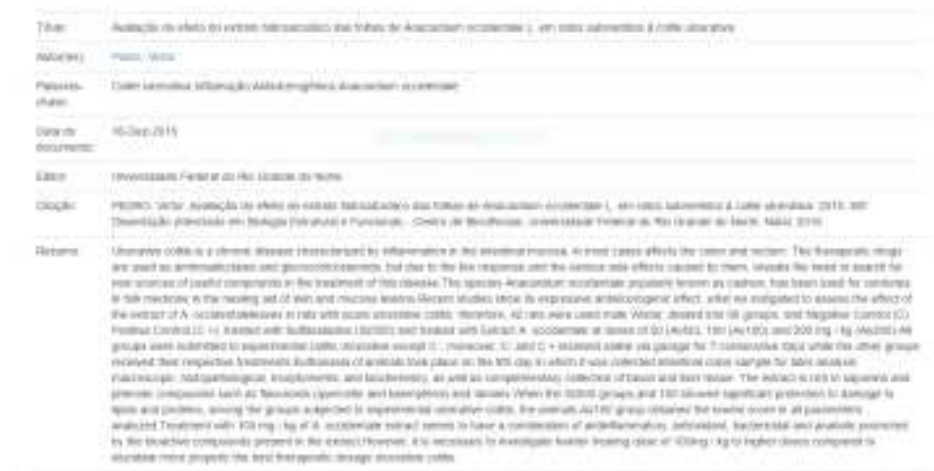

Fonte: http://repositorio.ufrn.br/>. Acesso em: 10 jun. 2016.

Quando tratamos da mediação dos informáticos estamos nos referindo quase sempre ao desenvolvimento da interface, tendo em vista que os repositórios já utilizam um software base, sendo ele o DSpace em sua grande maioria.

Figura 3 - Página inicial do RI UFRN

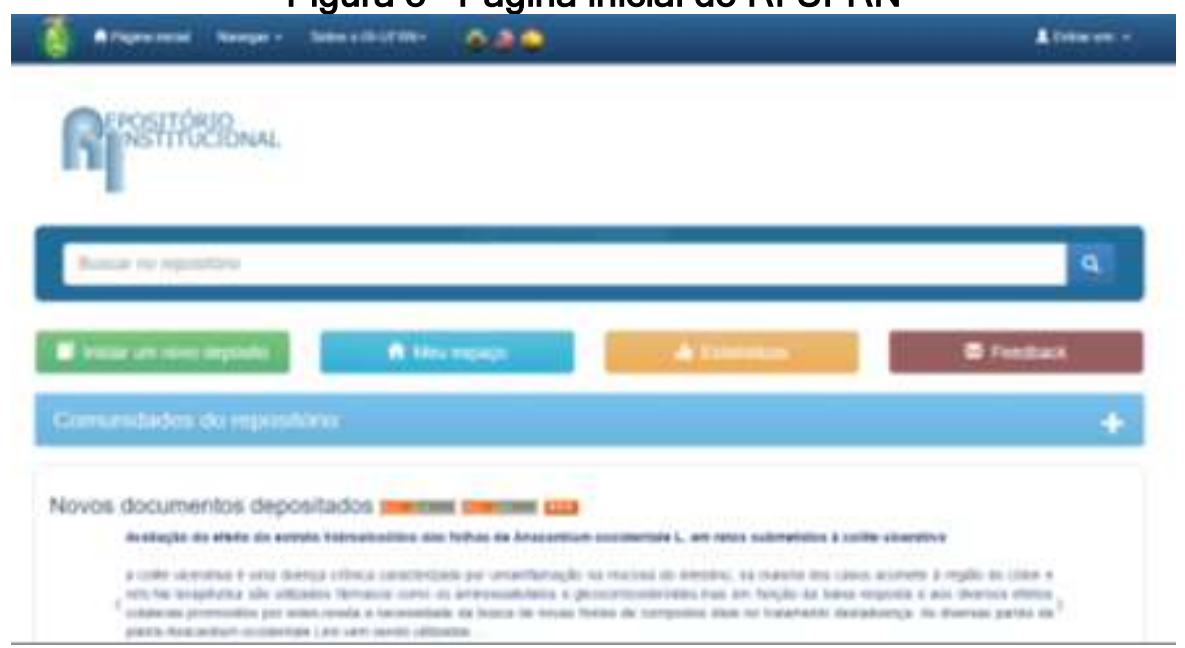

Fonte: http://repositorio.ufrn.br/>. Acesso em: 10 jun. 2016.

A mediação dos profissionais da informação acontece nos processos de seleção, organização, representação, armazenamento, preservação e disseminação da informação, no repositório ela se dá de forma interna principalmente na representação e seleção da informação que será disponibilizada no ambiente informacional em questão. 
Quando tratamos da mediação dos sujeitos informacionais tratamos da atividade realizada por eles no RI, o auto depósito.

Custódio e Vechiato elaboraram um quadro que esclarece as atividades de cada mediador no ambiente do Repositório Institucional da UFRN.

Quadro 1 - Ações infocomunicacionais e tecnológicas realizadas pelos diferentes mediadores no Repositório Institucional da UFRN

\begin{tabular}{|c|c|c|}
\hline Mediador & Ações & $\begin{array}{l}\text { Influência na encontrabilidade } \\
\text { da informação }\end{array}$ \\
\hline Sujeito informacional & $\begin{array}{l}\text { Depósito e preenchimento } \\
\text { dos metadados }\end{array}$ & $\begin{array}{l}\text { Quando o preenchimento } \\
\text { desses metadados é feito de } \\
\text { forma correta, é exercida uma } \\
\text { influência positiva na } \\
\text { encontrabilidade da informação, } \\
\text { pois possibilita o encontro } \\
\text { dessas informações de forma } \\
\text { rápida e precisa. No entanto, } \\
\text { mesmo com essa ação sendo } \\
\text { efetuada corretamente, existem } \\
\text { casos em que a encontrabilidade } \\
\text { dessa informação é prejudicada, } \\
\text { como é o caso das palavras- } \\
\text { chave, onde muitas vezes o } \\
\text { problema não se encontra no } \\
\text { preenchimento e sim na escolha } \\
\text { delas. }\end{array}$ \\
\hline Bibliotecário & $\begin{array}{l}\text { Conferência dos } \\
\text { metadados e auxilio aos } \\
\text { mediadores informáticos }\end{array}$ & $\begin{array}{l}\text { A verificação desses metadados } \\
\text { e do depósito é essencial, pois } \\
\text { mesmo com orientação, } \\
\text { inúmeras vezes os sujeitos } \\
\text { informacionais se confundem e } \\
\text { acabam colocando informações } \\
\text { incorretas, diante disso, essa } \\
\text { conferência faz com que todas } \\
\text { as informações, do título ao } \\
\text { nome do arquivo, sejam } \\
\text { disponibilizadas de forma } \\
\text { correta. Com a parceria com os } \\
\text { mediadores informáticos, é } \\
\text { possível fazer o Rl atender a } \\
\text { necessidade dos usuários, } \\
\text { influenciando diretamente, de } \\
\text { forma positiva, } \\
\text { encontrabilidade da informação. }\end{array}$ \\
\hline Informático & Customização do sistema & $\begin{array}{l}\text { Essa customização torna o RI } \\
\text { acessível e de fácil entendimento } \\
\text { para todos os usuários, incluindo } \\
\text { o sujeito informacional, que para } \\
\text { conseguir fazer o depósito do } \\
\text { seu trabalho precisa entender o } \\
\text { que está sendo pedido. }\end{array}$ \\
\hline
\end{tabular}

Fonte: Custódio e Vechiato (2014) 
A affordance é definida como "um princípio de usabilidade, relacionado aos incentivos e pistas atribuídos ao sistema que proporcionam aos sujeitos a realização de determinadas ações". (VECHIATO; VIDOTTI, 2014). Essas affordances colaboram com a orientação espacial. No repositório um exemplo facilmente observado de affordance são as informações sobre o RI UFRN que aparecem quando você passa o cursor do mouse pelo símbolo da RI.

Figura 4 - Exemplo de affordance no ícone do repositório

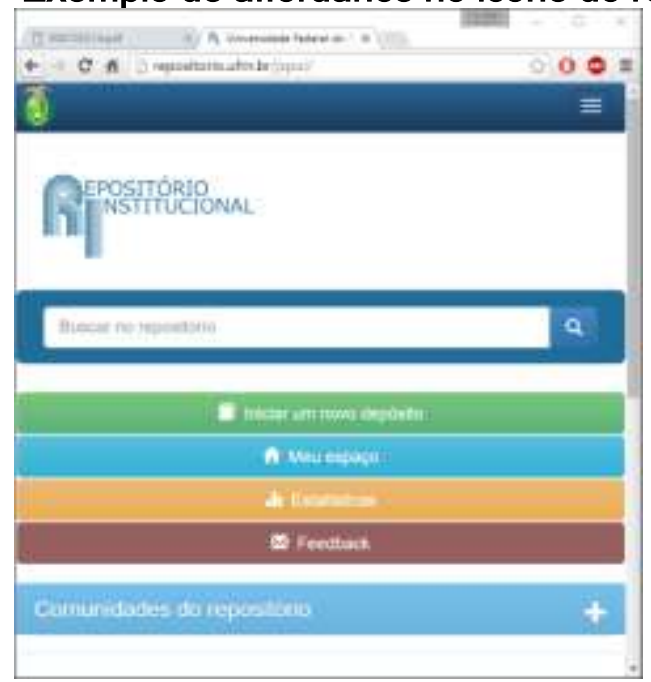

Fonte: http://repositorio.ufrn.br/>. Acesso em: 10 jun. 2016.

Figura 5 - Exemplo de affordance no ícone do repositório

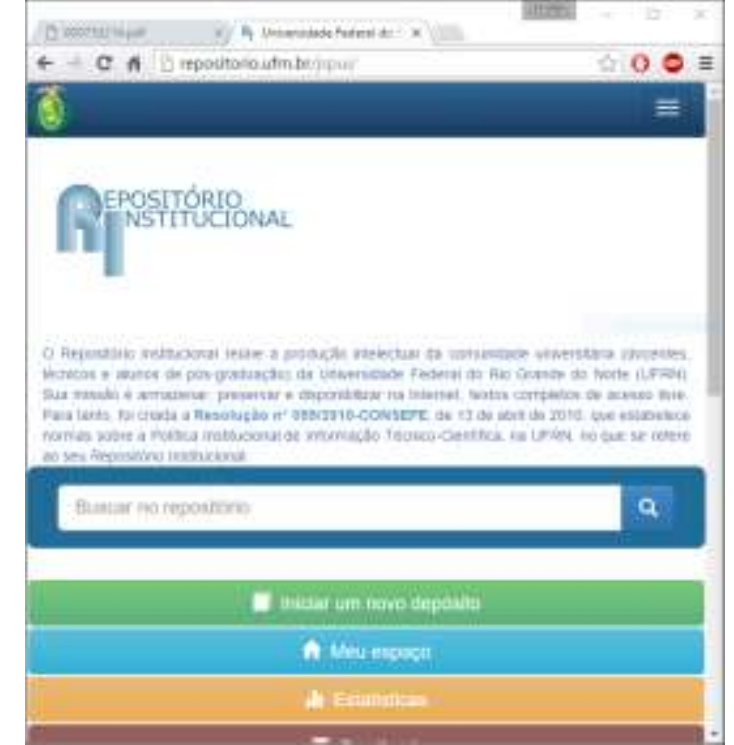

Fonte: http://repositorio.ufrn.br/>. Acesso em: 10 jun. 2016.

De acordo com Vechiato e Vidotti (2014) o termo wayfinding foi utilizado primeiramente pelo arquiteto Kevin Lynch, em 1960, para descrever o conceito de 
legibilidade ambiental, ou seja, os elementos do ambiente construído, como mapas, sinais, placas, etc.

No ambiente digital podemos visualizar esse conceito a partir de plugs, botões, imagens e etc que nos indicam o caminho que queremos seguir.

Figura 6 - Trilha de navegação

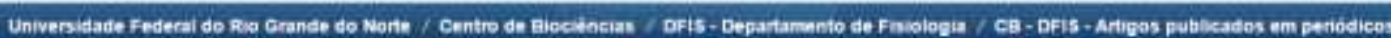

Fonte: http://repositorio.ufrn.br/>. Acesso em: 10 jun. 2016.

A descoberta de informações está relacionada com a facilidade que a interface possibilita o usuário de encontrar a informação desejada, atendendo as necessidades informacionais dele. Essa descoberta de informação está diretamente ligada com a acessibilidade e a usabilidade do ambiente. A facilidade de uso pode interferir na encontrabilidade de informação, assim como a usabilidade. Esses atributos podem ser observados não apenas no RI da UFRN, mas em todos os ambientes informacionais.

\footnotetext{
É importante considerar que a dificuldade de acesso e de uso tanto pode prejudicar a encontrabilidade a priori, ao impossibilitar a descoberta de informações por meio da navegação, quanto a posteriori, quanto o sujeito já encontrou a informação num mecanismo de busca, mas não consegue acessá-la e usá-la a contento (VECHIADO; VIDOTTI, 2014).
}

Quando tratamos de acessibilidade, como estamos tratando de Repositórios Institucionais, é importante levar em consideração a acessibilidade digital, a qual de acordo com Vechiato e Vidotti (2014, p. 142) "está associada à facilidade de acesso por todos aqueles que constituem o público-alvo de uma arquitetura da informação". Ou seja, os autores sugerem que a informação deve ser disponibilizada de modo que as pessoas, em diferentes condições físicas e ambientais, consigam encontra-la e acessá-la.

No entanto, não foi possível visualizar no RI UFRN nenhuma ferramenta de acessibilidade.

A usabilidade pode ser entendida como a facilidade de uso das interfaces, nos mais diversos tipos de sistemas e ambientes informacionais, o que de acordo com Vechiato e Vidotti (2014, p. 141) propicia a encontrabilidade da informação. Esses dois autores ainda afirmam que a usabilidade está intimamente relacionada com: a 
interação humano-computador, à ergonomia e às ciências cognitivas, à arquitetura da informação e ao comportamento informacional.

O design responsivo, de acordo com Teixeira (2011) consiste em programar um site de forma que os elementos que o compõem se adaptem automaticamente à largura de tela do dispositivo no qual ele está sendo visualizado.

De acordo com Teixeira (2011) um design responsivo inclui: adaptar o layout da página de acordo com a resolução em que está sendo visualizada; redimensionar as imagens automaticamente para que caibam na tela e para que não sobrecarreguem a transferência de dados em um celular, por exemplo; simplificar elementos da tela para dispositivos móveis, onde o usuário normalmente tem menos tempo e menos atenção durante a navegação; ocultar elementos desnecessários nos dispositivos menores; adaptar tamanho de botões e links para interfaces touch onde o ponteiro do mouse é substituído pelo dedo do usuário e utilizar de forma inteligente recursos mobile como geolocalização e mudança na orientação do aparelho (horizontal ou vertical).

No RI UFRN também possuímos design responsivo.

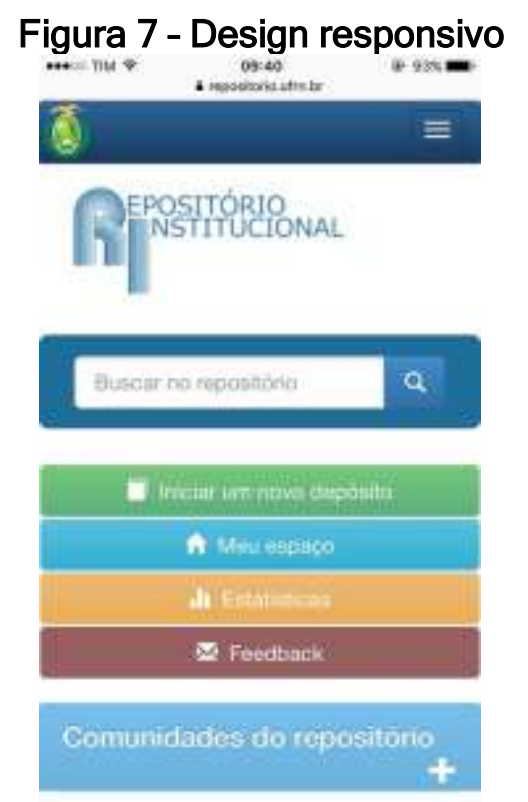

Fonte: http://repositorio.ufrn.br/>. Acesso em: 10 jun. 2016. 
A partir do esclarecimento desses atributos segue na próxima seção a proposta de um checklist para repositórios institucionais, elaborado com base na observação dos atributos da encontrabilidade da informação no repositório institucional da UFRN.

\section{PROPOSTA DE CHECKLIST}

O checklist foi elaborado com base nos atributos da encontrabilidade da informação propostos por Vechiato e Vidotti (2014) e a partir da observação do repositório institucional da UFRN. O instrumento é apresentado no Quadro 2 que segue:

Quadro 2 - Checklist para avaliação da encontrabilidade da informação em repositórios institucionais

\begin{tabular}{|c|c|c|c|c|}
\hline Atributos & $\begin{array}{c}\text { Diretrizes } \\
\end{array}$ & $\mathrm{s}$ & $\mathbf{N}$ & NA \\
\hline \multirow[b]{2}{*}{$\begin{array}{c}\text { Taxonomias } \\
\text { navegacionais }\end{array}$} & $\begin{array}{l}\text { As comunidades e coleções possuem } \\
\text { categorização adequada dos } \\
\text { conceitos/termos. }\end{array}$ & & & \\
\hline & $\begin{array}{l}\text { As comunidades e coleções existentes } \\
\text { possuem termos significativos e } \\
\text { coerentes que não dificultam seu } \\
\text { entendimento. }\end{array}$ & & & \\
\hline $\begin{array}{l}\text { Instrumentos de } \\
\text { controle terminológico }\end{array}$ & $\begin{array}{l}\text { Utiliza vocabulários controlados para a } \\
\text { representação dos documentos } \\
\text { disponibilizados. }\end{array}$ & & & \\
\hline Folksonomias & $\begin{array}{l}\text { Permite a inserção de tags aos } \\
\text { documentos. }\end{array}$ & & & \\
\hline \multirow[t]{2}{*}{ Metadados } & $\begin{array}{l}\text { Utiliza padrão de metadados coerente } \\
\text { com os tipos de documentos } \\
\text { determinados pela política do } \\
\text { repositório. }\end{array}$ & & & \\
\hline & $\begin{array}{l}\text { Os documentos são representados por } \\
\text { uma descrição completa dos } \\
\text { metadados. }\end{array}$ & & & \\
\hline \multirow{3}{*}{$\begin{array}{l}\text { Mediação dos } \\
\text { informáticos }\end{array}$} & $\begin{array}{l}\text { Foi realizada a customização da } \\
\text { interface. }\end{array}$ & & & \\
\hline & Possui versão mais atualizada. & & & \\
\hline & Realizou a criação de plug-ins. & & & \\
\hline \multirow{2}{*}{$\begin{array}{l}\text { Mediação dos } \\
\text { profissionais da } \\
\text { informação }\end{array}$} & $\begin{array}{l}\text { O repositório disponibiliza tutorial de } \\
\text { submissão. }\end{array}$ & & & \\
\hline & $\begin{array}{l}\text { Possui meios para o usuário entrar em } \\
\text { contato. }\end{array}$ & & & \\
\hline
\end{tabular}




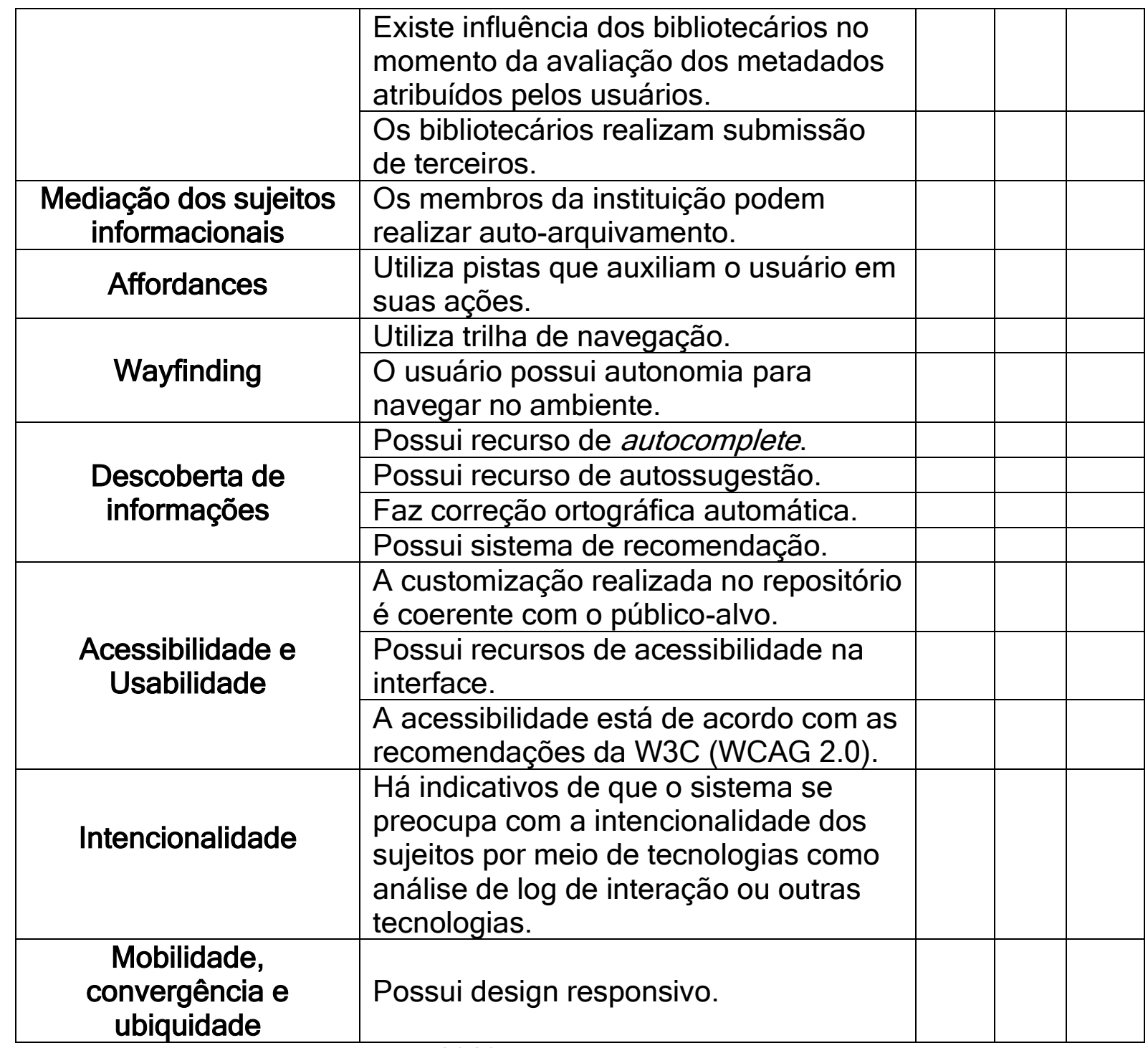

Fonte: Dados da pesquisa, 2016

O checklist apresenta três alternativas de resposta para cada diretriz, sendo $\mathbf{S}$ para Sim, quando a diretriz é satisfeita; $\mathbf{N}$ para Não, quando a diretriz não é satisfeita; e NA para Não Aplicável, caso a diretriz não se adeque ao contexto do repositório institucional analisado.

Após a observação dos treze atributos da encontrabilidade da informação propostos por Vechiato e Vidotti (2014) no Repositório Institucional da UFRN, da elaboração do checklist e da breve análise sobre esses atributos podemos perceber que nem todos eles podem ser encontrados no referido ambiente informacional digital.

Em relação as taxonomias navegacionais pensamos que o RI UFRN apresenta-as de forma satisfatória, essas taxonomias podem ser facilmente visualizadas em comunidades e coleções. No entanto, a divisão utilizada deixa a desejar, pois a divisão utilizada não é coerente entre si. 
As folksonomias não são utilizadas no RI UFRN, no entanto acreditamos que pode ser levado a discussão a inserção delas, tendo em vista a necessidade de participação dos usuários em todos os ambientes digitais atualmente.

A descrição por metadados no ambiente analisado também é satisfatória, tendo em vista que são os próprios usuários depositantes que fazem essa inserção e que antes do material ser disponibilizado passa por uma conferência dos profissionais da informação responsáveis pelo RI.

A mediação dos usuários é coerente com a proposta do ambiente, mas poderia ir além com o uso de folksnomias. A mediação dos profissionais da informação também pode ser vista como coerente com a proposta do repositório, necessitando apenas de mais contato com os mediadores informáticos para possibilitar a melhoria de alguns aspectos do RI UFRN. Os mediadores informáticos poderiam ir além da customização básica e corrigir os erros do ambiente com mais eficácia.

As affordances do repositório são satisfatórias e interessantes. O wayfinding também está presente no RI UFRN e é bastante satisfatório, possuindo trilhas de navegação que orientam o usuário no processo do depósito, por exemplo.

A descoberta de informações está presente em todos os ambientes informacionais. Não conseguimos encontrar nenhum recurso de acessibilidade no RI UFRN, o que é preocupante e sugerimos a inserção dos mais básicos, como aumento de fonte e contraste de forma imediata. Um ponto positivo do RI UFRN é o uso de design responsivo.

De acordo com as definições dos recursos de acessibilidade e de usabilidade utilizados no artigo, podemos perceber que o RI UFRN não possui recursos de acessibilidade e de usabilidade.

A página inicial do design responsivo é totalmente compatível com smarthphones.

Podemos perceber que o RI UFRN atende a maioria das necessidades informacionais de seus usuários, mas ainda assim precisa de melhorias para propiciar uma encontrabilidade da informação completa para os seus usuários.

\section{CONSIDERAÇÕES FINAIS}

Com o objetivo de elaborar um instrumento de avaliação para repositórios institucionais, procurou-se inicialmente estudar os atributos da encontrabilidade da 
informação propostos por Vechiato e Vidotti (2014) e estuda-los em um ambiente informacional digital. Escolhemos o Repositório Institucional da Universidade Federal do Rio Grande do Norte como forma de exemplificar esses atributos e assim tornar possível observar o comportamento deles. A partir dessa observação conseguimos elaborar o checklist apresentado anteriormente.

O checklist foi aplicado no RI UFRN para observarmos a sua efetividade como instrumento de avaliação. A partir dessa constatação propõe-se aplicar esse checklist nos demais repositórios institucionais do Brasil como instrumento de avaliação desses ambientes e realizar, de fato, uma análise dos ambientes selecionados.

O objetivo da pesquisa foi atingido a partir do momento em que foi possível aplicar o checklist no repositório institucional da UFRN e constatar a necessidade de melhorias do ambiente informacional.

\section{REFERÊNCIAS}

CUSTÓDIO, N. C.; VECHIATO, F. L. Mediação infocomunicacional no contexto da encontrabilidade da informação: uma análise do processo de autoarquivamento no repositório institucional da Universidade Federal do Rio Grande do Norte. Biblionline, João Pessoa, v. 1, n. 12, p.3-13, maio 2016. Disponível em: <http://periodicos.ufpb.br/ojs2/index.php/biblio/article/view/28235/15346>. Acesso em: 17 jul. 2016.

GOMES, M. J.; ROSA, F. Dos promotores aos utilizadores: estudos sobre o RepositóriUM. In: GOMES, Maria João; Rosa, Flávia (Org.) - Repositórios institucionais: democratizando o acesso ao conhecimento. Salvador, EDUFBA, 2010. p.153-203.

MARCONI, M. A.; LAKATOS, Eva Maria. Fundamentos da metodologia científica. 7. ed. São Paulo: Atlas, 2010.

MORVILLE, P. Ambient findability. Sebastopol: O’Really, 2005.

NEVES, J. L. Pesquisa qualitvativa: características, usos e possibilidades. Caderno de Pesquisas em Administração, São Paulo, v. 1, n. 3, 1996. Disponível em: < http://www.unisc.br/portal/upload/com_arquivo/pesquisa_qualitativa_caracteristicas_ usos_e_possibilidades.pdf >. Acesso em: 14 jul. 2015. 
REPOSITÓRIO Institucional da Universidade Federal do Rio Grande do Norte. Disponível em: < http://repositorio.ufrn.br/>. Acesso em: 10 jun. 2016.

RODRIGUES, A. M. F. Repositórios institucionais de acesso livre: estudo de produção e uso. 2011. 183 f. Dissertação (Mestrado em Ciência da Informação) Universidade do Porto, Porto, 2011. Disponível em: < http://repositorioaberto.up.pt/bitstream/10216/61655/1/000148784.pdf>. Acesso em: 24 ago. 2015.

RODRIGUES, E. Acesso livre ao conhecimento: a mudança do sistema de comunicação da ciência e os profissionais de informação. Cadernos BAD, v.1, 2004. Disponível em: <http://www.bad.pt/publicacoes/index.php/cadernos/ article/view/836/835> Acesso em: 5 jan. 2016.

SAYÃO, L. F. et al. Implantação e gestão de repositórios institucionais: políticas, memória, livre acesso e preservação. Salvador: EDUFBA, 2009. Disponível em: $<$ https://repositorio.ufba.br/ri/bitstream/ufba/473/3/ implantacao_repositorio_web.pdf>. Acesso em: 16 dez. 2015.

TEIXEIRA, Fabricio. O que é responsive web design?. 2011. Disponível em: $<$ http://arquiteturadeinformacao.com/mobile/o-que-e-responsive-web-design/>. Acesso em: 1 ago. 2016.

VECHIATO, F. L.; VIDOTTI, S. A. B. G. Encontrabilidade da informação. 1. ed. São Paulo: Cultura Acadêmica, 2014. 